\title{
A CuNi/C Nanosheet Array Based on a Metal-Organic Framework Derivate as a Supersensitive Non-Enzymatic Glucose Sensor
}

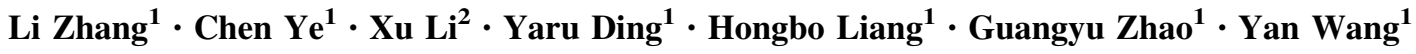

Received: 26 September 2017/ Accepted: 23 November 2017/Published online: 22 December 2017

(C) The Author(s) 2017. This article is an open access publication

\section{Highlights}

- $\mathrm{CuNi} / \mathrm{C}$ nanosheet arrays were prepared by pyrolyzing $\mathrm{Ni}$-based metal organic framework and successive $\mathrm{Cu}$ electrodeposition.

- The prepared arrays exhibited high sensitivity $\left(17.12 \mathrm{~mA} \mathrm{mM}^{-1} \mathrm{~cm}^{-2}\right)$ and low detection limit $(66.67 \mathrm{nM})$ as nonenzymatic glucose sensors.

- The electrode exhibits good reusability, reproducibility, and stability and thereby caters to the practical use of glucose sensors.

\begin{abstract}
Bimetal catalysts are good alternatives for nonenzymatic glucose sensors owing to their low cost, high activity, good conductivity, and ease of fabrication. In the present study, a self-supported $\mathrm{CuNi} / \mathrm{C}$ electrode prepared by electrodepositing $\mathrm{Cu}$ nanoparticles on a Ni-based metal-organic framework (MOF) derivate was used as a non-enzymatic glucose sensor. The porous construction and carbon scaffold inherited from the Ni-MOF guarantee good kinetics of the electrode process in electrochemical glucose detection. Furthermore, $\mathrm{Cu}$ nanoparticles disturb the array structure of MOF derived films and evidently enhance their electrochemical performances in glucose
\end{abstract}

Electronic supplementary material The online version of this article (https://doi.org/10.1007/s40820-017-0178-9) contains supplementary material, which is available to authorized users.

Yan Wang

wangy_msn@hit.edu.cn

1 School of Chemistry and Chemical Engineering, Harbin Institute of Technology, Harbin 150080, Heilongjiang, People's Republic of China

2 Department of Ophthalmology, Second Hospital, Jilin University, Changchun 130022, Jilin, People's Republic of China

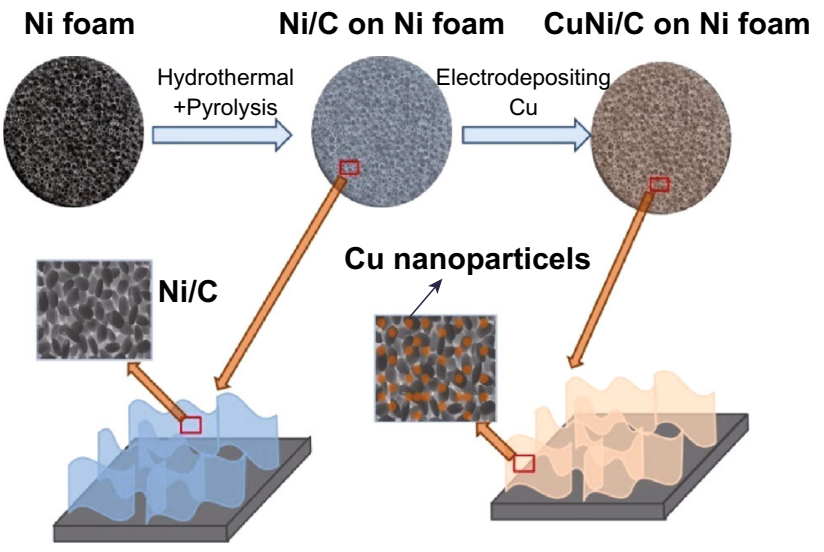

detection. Electrochemical measurements indicate that the $\mathrm{CuNi} / \mathrm{C}$ electrode possesses a high sensitivity of $17.12 \mathrm{~mA} \mathrm{mM}^{-1} \mathrm{~cm}^{-2}$, a low detection limit of $66.67 \mathrm{nM}$, and a wider linearity range from 0.20 to $2.72 \mathrm{mM}$. Additionally, the electrode exhibits good reusability, reproducibility, and stability, thereby catering to the practical use of glucose sensors. Similar values of glucose concentrations in human blood serum samples are detected with our electrode and with the method involving glucose-6phosphate dehydrogenase; the results further demonstrate the practical feasibility of our electrode. 
Keywords Non-enzymatic glucose sensor - Nanoparticle · Nanosheet array $\cdot$ Self-supported electrode $\cdot$ Copper-nickel bimetal catalyst

\section{Introduction}

Quantitative analysis of glucose in blood is vital for diabetes mellitus diagnosis, and obtaining these values conveniently and accurately is especially desirable $[1,2]$. Despite their high sensitivity and selectivity, classical electrochemical enzyme sensors still present disadvantages including high cost, instability, and poor reproducibility. These drawbacks are due to the intrinsic defects of glucose oxidase or glucose dehydrogenase [1-5]. Therefore, there is a tremendous need to develop inexpensive and robust non-enzymatic sensors that can accurately detect glucose in blood. Diverse catalysts, such as carbon composites, noble metals, transition metals, transition metal oxides and hydroxides, metal alloys, and bimetals, were explored as non-enzymatic glucose sensors [6-23]. Among these, transition metals attract considerable attention owing to their low cost, high conductivity, good catalytic activity, and facile preparation [24-41]. In various transition metals, $\mathrm{Ni}$ nanocrystals exhibit a series of outstanding performances when they are used as glucose sensors including high sensitivity, low detection limit, and good stability $[6,42,43]$. However, the narrow linearity range of $\mathrm{Ni}$ catalysts in glucose detection restricts their practicability [43]. A typical method to solve this issue involves introducing another metal to form a bimetal catalyst that enhances the properties by completely using the components in catalysts [44, 45]. Previous studies [44-46] indicate that $\mathrm{Cu}$ metal possesses a significantly wider linearity range in glucose detection when compared with $\mathrm{Ni}$ [47, 48], and thus researchers explored several bimetal catalysts by combining the advantages of $\mathrm{Cu}$ and $\mathrm{Ni}$ with comprehensive virtues. Wang [49] reported a CuNi bimetal catalyst that presents a wide linearity range from $7 \mu \mathrm{M}$ to $23.67 \mathrm{mM}$ that considerably exceeds those of $\mathrm{Ni}$ catalysts. $\mathrm{Li}$ et al. [50] indicated that $\mathrm{CuNi}$ nanocrystal composite behaved much better than a catalyst with a single component due to the bi-functional effect. Researchers also compared electrochemical properties of carbon nanotubes modified with $\mathrm{CuNi}$ to those modified with a single metal. The results demonstrated that bimetals exhibited higher response currents and lower detection limit [51, 52]. In a previous study, we reported a self-supported electrode constructed with porous $\mathrm{Ni} / \mathrm{C}$ nanosheets derived from $\mathrm{Ni}$ based metal organic frameworks (MOFs) [43]. The electrode exhibited attractive characteristics with respect to glucose detection, owing to its unique hierarchically porous structure, small crystals, and a wide-spread carbon scaffold. However, a narrow linearity range $(0.15 \mu \mathrm{M}-$ $1.48 \mathrm{mM}$ ) was the only disadvantage of this electrode. In order to compensate for this drawback, in the present study, $\mathrm{Cu}$ was introduced into the porous nanosheet arrays electrode to form a self-supported $\mathrm{CuNi} / \mathrm{C}$ glucose sensor.

Furthermore, MOFs derivates display significant potential when they are used in electrocatalysis and electrochemical energy storage owing to their porous structure, ultra-small active materials, and homogeneously conductive carbon scaffold. Additionally, the homogeneous distribution of pores, active grains, and carbon derived from the unique construction of MOFs enables their derivates to act as good candidates for self-supported electrodes. We can integrate conductive frame, mass transport channels, and nanoscale active materials by using a bottom-up process as opposed to the traditional pasting method for preparing electrodes. In this study, the electrodes were prepared by electrodeposited $\mathrm{Cu}$ nanoparticles on the porous $\mathrm{Ni} / \mathrm{C}$ nanosheet arrays that were prefabricated via pyrolyzing Ni-based MOFs on $\mathrm{Ni}$ foam [43]. CuNi/C electrodes inherit the superiority of hierarchically porous structures and good conductivity from $\mathrm{Ni} / \mathrm{C}$ substrates and thereby enable the $\mathrm{CuNi} / \mathrm{C}$ glucose sensor to perform with a high sensitivity of $17.12 \mathrm{~mA} \mathrm{mM}{ }^{-1} \mathrm{~cm}^{-2}$ and a low detection limit of $66.67 \mathrm{nM}$. The compensation of $\mathrm{Cu}$ nanoparticles causes the $\mathrm{CuNi} / \mathrm{C}$ electrodes to also exhibit a wider linearity range $(0.2 \mu \mathrm{M}-2.72 \mathrm{mM})$ when compared with the $\mathrm{Ni} / \mathrm{C}$ electrode.

\section{Experimental}

\subsection{Materials}

All reagents are analytical reagents, and they were used without further purification. Specifically, $\mathrm{CuSO}_{4} \cdot 5 \mathrm{H}_{2} \mathrm{O}$, $\mathrm{Na}_{2} \mathrm{SO}_{4}, \quad \mathrm{NiSO}_{4} \cdot 6 \mathrm{H}_{2} \mathrm{O}$, aqueous ammonia (25-28\%), $\mathrm{NiCl}_{2} \cdot 6 \mathrm{H}_{2} \mathrm{O}, \mathrm{C}_{8} \mathrm{H}_{6} \mathrm{O}_{4}, \mathrm{~N}, \mathrm{~N}$-dimethylacetamide (DMF), D-(+)-Glucose, dopamine (DA), L-ascorbic acid (AA), acetaminophen, fructose, sucrose, folic acid, and L-cysteine were purchased from Sinopharm Chemical Reagent Co., Ltd (China). Additionally, $\mathrm{K}_{2} \mathrm{~S}_{2} \mathrm{O}_{8}$ was purchased from Tianjin Kaitong Chemical Reagent Co., Ltd. (Tianjin, China). Uric acid (UA) was purchased from Alfa Aesar.

\subsection{Preparation of $\mathrm{CuNi} / \mathrm{C}$ Electrodes}

The electrodes were prepared by electrodepositing $\mathrm{Cu}$ nanoparticles on the porous $\mathrm{Ni} / \mathrm{C}$ nanosheet arrays that were prefabricated via pyrolyzing $\mathrm{Ni}-\mathrm{MOF}$ on $\mathrm{Ni}$ foam [43]. First, $0.11 \mathrm{~g} \mathrm{NiCl}_{2} \cdot 6 \mathrm{H}_{2} \mathrm{O}$ and $0.08 \mathrm{~g} \mathrm{C}_{8} \mathrm{H}_{6} \mathrm{O}_{4}$ were dissolved in a $25-\mathrm{mL}$ mixture of DMF/ethanol/water (v:v:v $=14: 1: 1$ ). The solution was mixed by magnetic stirring for 
30 min and then poured into a 40-mL Teflon-lined autoclave with pieces of $\mathrm{Ni}$ foam $\left(2 \times 1 \mathrm{~cm}^{2}\right)$. The hydrothermal reaction was performed in an oven at $125^{\circ} \mathrm{C}$ for $24 \mathrm{~h}$. The Ni foam was removed after the autoclave naturally cooled to room temperature. The foam was alternately rinsed with absolute ethanol and DI water several times and then dried overnight. Furthermore, Ni/C arrays were obtained by pyrolyzing the Ni-MOF in $\mathrm{Ar}$ atmosphere at $420{ }^{\circ} \mathrm{C}$ for $4 \mathrm{~h}$ with a ramp rate of $2{ }^{\circ} \mathrm{C}$ $\mathrm{min}^{-1}$. Second, the electrodeposition of $\mathrm{Cu}$ nanoparticles was conducted in a three-electrode system with $\mathrm{Ni} / \mathrm{C}$ arrays as a working electrode by using a Pt foil $\left(1 \times 1 \mathrm{~cm}^{2}\right)$ as a counter electrode and a saturated calomel electrode as a reference electrode. Moreover, $\mathrm{Cu}$ depositing was performed in an electrolyte of $0.1 \mathrm{M} \mathrm{CuSO}_{4}+0.2 \mathrm{M} \mathrm{Na}_{2} \mathrm{SO}_{4}$ by using a potentiostatic method at $-1.4 \mathrm{~V}$. Finally, the obtained $\mathrm{CuNi} / \mathrm{C}$ electrodes were rinsed with DI water and ethanol several times and dried overnight for further characterization.

\subsection{Physical Characterization and Electrochemical Measurements of the $\mathrm{CuNi} / \mathrm{C}$ Electrodes}

Scanning electron microscope (SEM) images and energydispersive spectra (EDS) were obtained on a Hitachi Su8100 (Japan). The X-ray diffraction (XRD) patterns were obtained on a PANalytical X'pert PRO X-ray diffractometer with $\mathrm{Cu} \mathrm{K} \alpha$ radiation $(\lambda=1.54 \AA)$. Raman spectra were recorded from 750 to $3500 \mathrm{~cm}^{-1}$ on a Renishaw 2000 Confocal Raman Microprobe (Renishaw Instruments, England) by using a $514.5 \mathrm{~nm}$ argon ion laser. Transmission electron microscope (TEM) images were obtained on a JEOL-2100 (Japan). The electrochemical measurements were taken on a CHI 660D workstation (CH Instruments, China). A three-electrode system was used for testing with the $\mathrm{CuNi} / \mathrm{C}$ as working electrode (apparent area is $1 \times 1 \mathrm{~cm}^{2}$ ) by using a $\mathrm{Pt}$ foil and an $\mathrm{Ag} / \mathrm{AgCl}$ electrode as counter and reference electrodes, respectively. All potentials were relative to the $\mathrm{Ag} / \mathrm{AgCl}$ (sat'd $\mathrm{KCl}$ ) electrode in $0.1 \mathrm{M} \mathrm{NaOH}$ electrolyte. Cyclic voltammetry (CV) was performed in the quiescent solution, and amperometric measurements were taken under magnetic stirring. With respect to the 60-day stability test, our electrode was washed with DI water and dried naturally at room temperature for the next test (after every test at an interval of 5 days).

\section{Results and Discussion}

The $\mathrm{CuNi} / \mathrm{C}$ electrodes were prepared according to the schematic diagram shown in Fig. 1. Porous Ni/C nanosheet membranes derived from Ni-terephthalic acid MOFs
$\left(\mathrm{Ni}_{3}(\mathrm{OH})_{2}\left(\mathrm{C}_{8} \mathrm{H}_{4} \mathrm{O}_{4}\right)_{2}\left(\mathrm{H}_{2} \mathrm{O}\right)_{4}\right)$ were successfully anchored on a $\mathrm{Ni}$ foam substrate by using hydrothermal treatment with successive pyrolysis [43]. Subsequently, CuNi/C electrodes were prepared by electrodepositing $\mathrm{Cu}$ nanoparticles on $\mathrm{Ni} / \mathrm{C}$ electrodes. The quantity and size of $\mathrm{Cu}$ nanoparticles were adjusted by adopting different depositing times. As shown in Fig. S1, the surface morphologies of the samples in which the deposited time exceeds $20 \mathrm{~s}$ were compared with the raw $\mathrm{Ni} / \mathrm{C}$ electrode. As shown in Fig. 2a, b, there is no obvious change when the depositing time is 5 or $10 \mathrm{~s}$, and this indicates that a low amount of $\mathrm{Cu}$ is deposited on the $\mathrm{Ni} / \mathrm{C}$ surface. Conversely, excessive $\mathrm{Cu}$ deposition blocks the channels between the nanosheets when the depositing time exceeds 20 s (i.e., 50 or $100 \mathrm{~s}$ ). This is unfavorable for the mass transport while using the electrodes for glucose detection. The amperometric responses of $\mathrm{CuNi} / \mathrm{C}$ electrodes with different $\mathrm{Cu}$ depositing times describe the relationship between the catalytic ability and the $\mathrm{Cu}$ amounts as shown in Fig. 3 . Evidently, the sample with $\mathrm{Cu}$ depositing time of $20 \mathrm{~s}$ exhibits the highest response current, thereby indicating the optimal preparation parameter. As shown in Fig. 2f, with the optimal preparation parameter, the EDS results demonstrate that the atom ratio of $\mathrm{C} / \mathrm{Ni} / \mathrm{Cu}$ is $10: 2: 1$. This indicates that the primary component of $\mathrm{CuNi} / \mathrm{C}$ arrays is carbon. In contrast, the element mapping (shown in Fig. S2) reveals the homogeneous distribution of $\mathrm{C}, \mathrm{Cu}$, and $\mathrm{Ni}$ on the electrode. The TEM images of raw $\mathrm{Ni} / \mathrm{C}$ nanosheets (Fig. S3a, b) exhibit the homogeneous distribution of $\mathrm{Ni}$ and $\mathrm{C}$ nanoparticles in the nanosheets as described in detail in a previous study [43]. After $\mathrm{Cu}$ depositing, larger nanoparticles were detected on the nanosheets heterogeneously (as denoted by red arrows in Fig. S3c, d), and this is consistent with the SEM results. Figure $\mathrm{S} 4$ shows a more comprehensive morphology detail of $\mathrm{CuNi} / \mathrm{C}$ electrode. Evidently, the $\mathrm{Cu}$ nanoparticles are homogeneously distributed on the $\mathrm{Ni} / \mathrm{C}$ nanosheets without

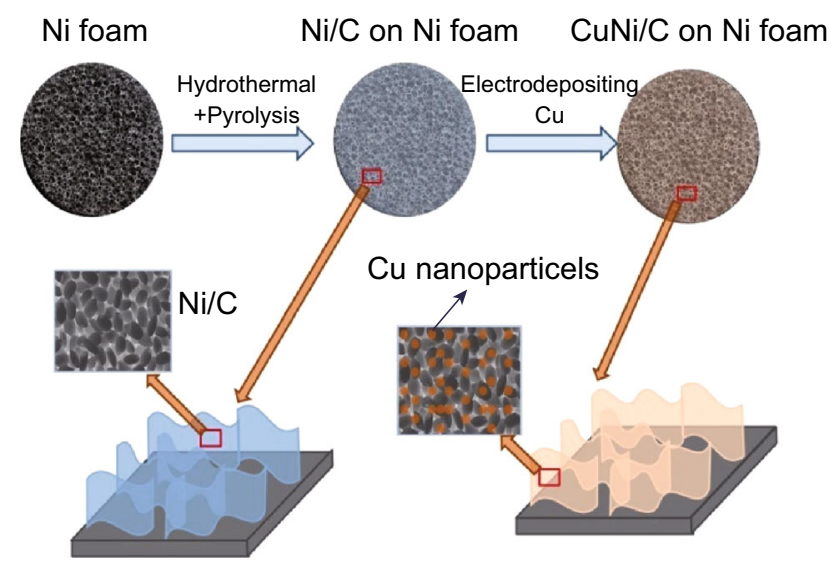

Fig. 1 Schematic diagram of preparing $\mathrm{CuNi} / \mathrm{C}$ electrodes 

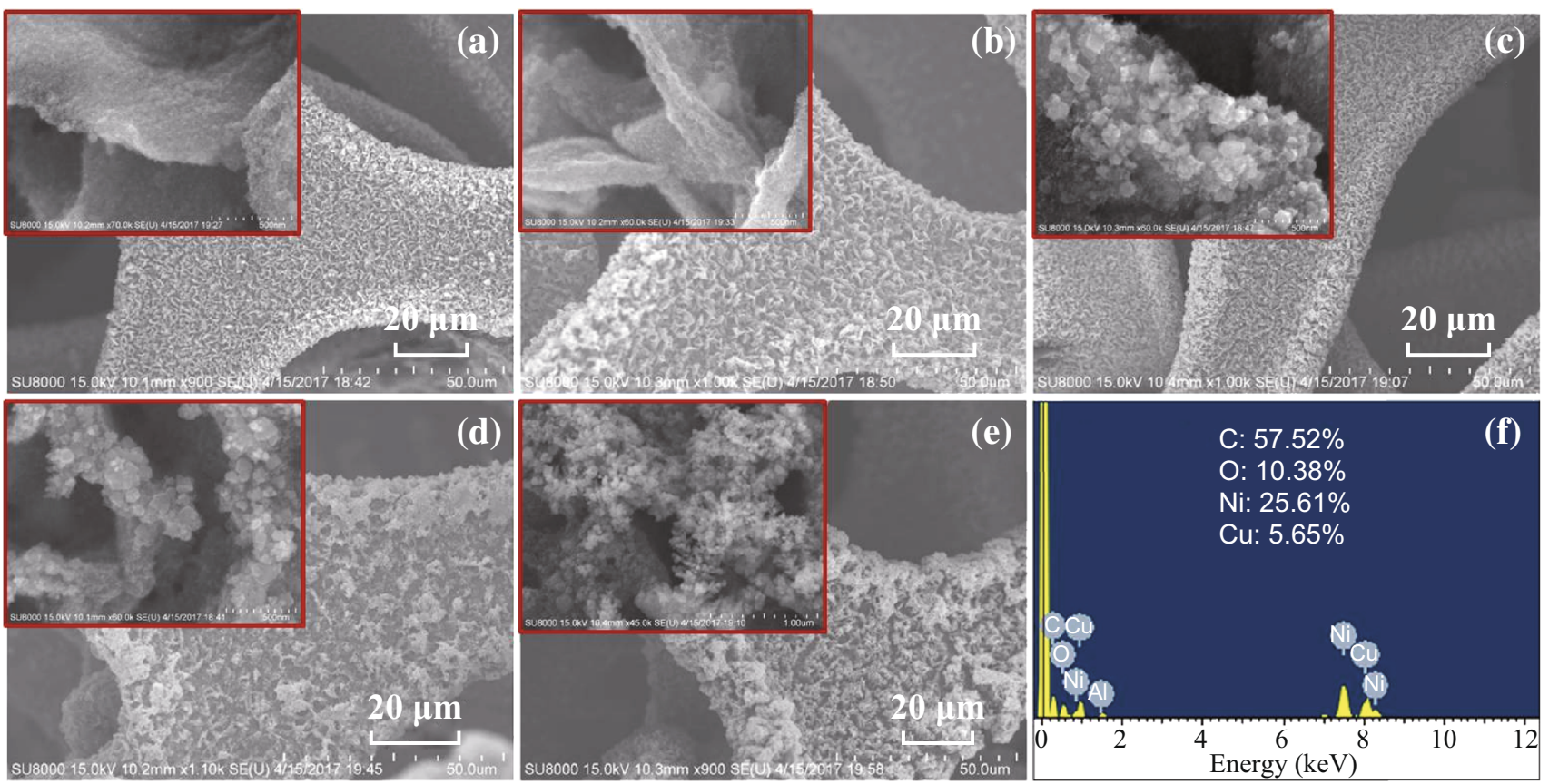

Fig. 2 SEM images of $\mathrm{CuNi} / \mathrm{C}$ electrodes prepared with different $\mathrm{Cu}$ depositing times: a $5 \mathrm{~s}, \mathbf{b} 10 \mathrm{~s}, \mathbf{c} 20 \mathrm{~s}$, d $50 \mathrm{~s}$, and e $100 \mathrm{~s}$. The insets show the corresponding high-resolution images, and $\mathbf{f}$ EDS pattern on $\mathbf{c}$

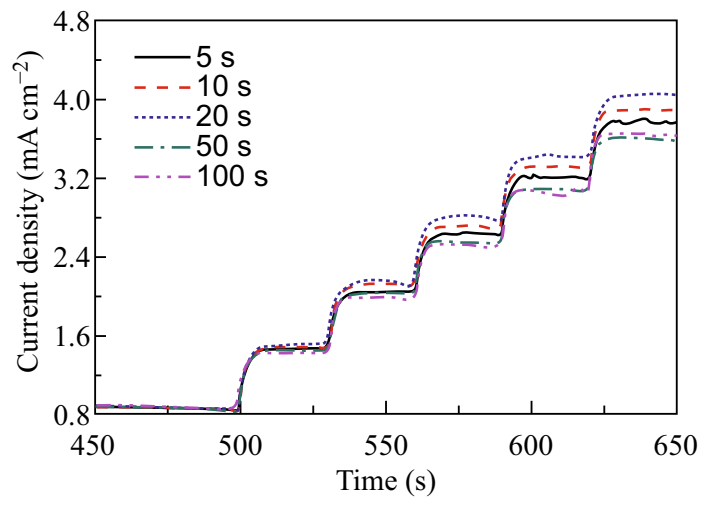

Fig. 3 Amperometric responses of $\mathrm{CuNi} / \mathrm{C}$ obtained from different $\mathrm{Cu}$ depositing time, and the detail shows the consecutive addition of $20 \mu \mathrm{M}$ glucose into $0.1 \mathrm{M} \mathrm{NaOH}$ at $0.54 \mathrm{~V}$

interference with respect to the array structure and micrometer channels. This aids in improving the catalytic ability of $\mathrm{Ni} / \mathrm{C}$ while not disturbing the kinetics in electrochemical detection.

The existence of $\mathrm{Cu}$ in the as-prepared electrodes is further confirmed by XRD analyses as shown in Fig. 4. A small peak assigned to $\mathrm{Cu}(111)$ (JCPDS card No. 04-0836) is detected at $43.3^{\circ}$ with the exception of strong diffraction peaks of $\mathrm{Ni}$ from Ni/C substrates and Ni foam. For comparison purposes, the XRD pattern of porous $\mathrm{Ni} / \mathrm{C}$ on $\mathrm{Ni}$ foam is shown in Fig. S5. The results indicate that the pattern of $\mathrm{Ni} / \mathrm{C}$ on $\mathrm{Ni}$ foam primarily exhibits $\mathrm{Ni}$ diffraction peaks (JCPDS card No. 04-0850). In order to further

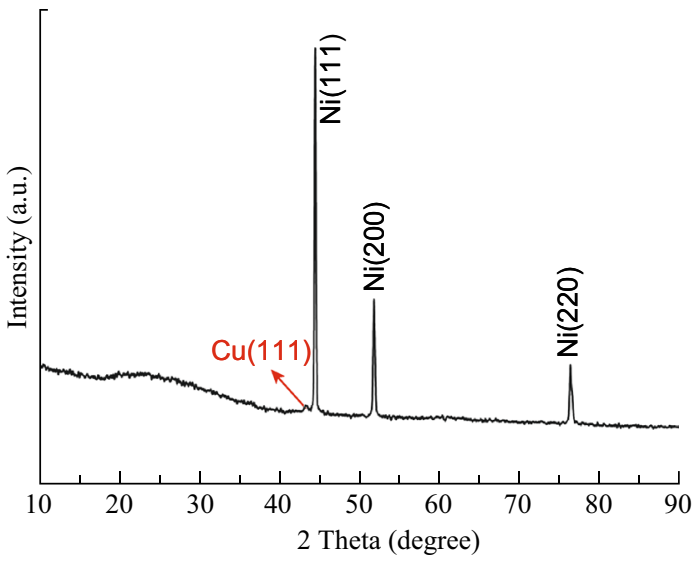

Fig. 4 XRD pattern of $\mathrm{CuNi} / \mathrm{C}$ electrodes

exclude the interference of $\mathrm{Ni}$ foam, $\mathrm{Ni} / \mathrm{C}$ powder prepared with the same condition is also measured by XRD analyses. Evidently, the Ni primary content in the powder reveals that the Ni catalyst on electrodes results from the pyrolysis of Ni-MOF. Conversely, the bump at approximately $26^{\circ}$ is ascribed to the amorphous carbon from pyrolysis.

The $\mathrm{CuNi} / \mathrm{C}$ electrodes were activated by $\mathrm{CV}$ ranging from -0.9 to $0.9 \mathrm{~V}$ in $0.1 \mathrm{M} \mathrm{NaOH}$ prior to their use as glucose sensors. Figure 5a shows the $\mathrm{CV}$ curves of a $\mathrm{CuNi} /$ $\mathrm{C}$ electrode in 60 cycles, at a scanning rate of $20 \mathrm{mV} \mathrm{s}^{-1}$. In the initial cycles, the active sites on the electrodes experience a conversion from $\mathrm{Ni}$ and $\mathrm{Cu}$ to $\mathrm{Ni}^{3+}$ and $\mathrm{Cu}^{3+}$ and then back to $\mathrm{Ni}$ and $\mathrm{Cu}$, respectively, in the scan, and the process and their inverse processes can be expressed as 

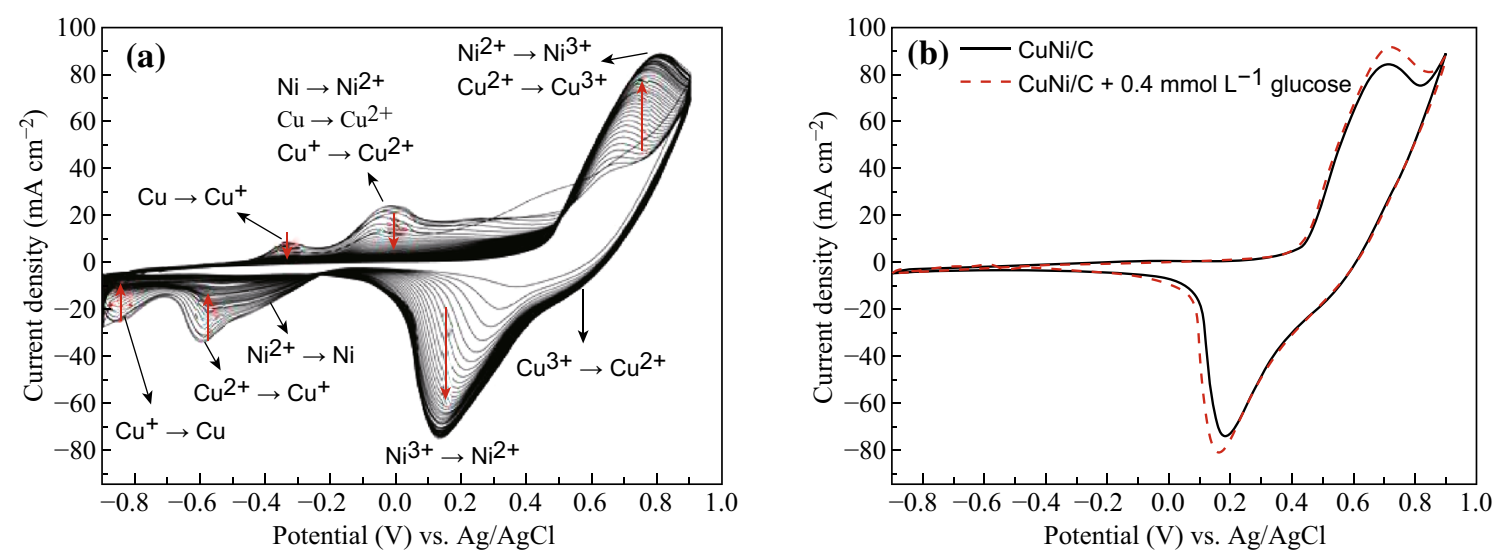

Fig. 5 a Activated $\mathrm{CuNi} / \mathrm{C}$ electrodes in $0.1 \mathrm{M} \mathrm{NaOH}$ by $\mathrm{CV}$ for 60 cycles. b CVs of activated electrodes in $0.1 \mathrm{M} \mathrm{NaOH}$ and $0.1 \mathrm{M}$ $\mathrm{NaOH}+0.4 \mathrm{mM}$ glucose. The $\mathrm{CV}$ measurements are performed in a three-electrode system by using Pt foil as counter electrode, and $\mathrm{Ag} / \mathrm{AgCl}$ as a reference electrode. The scan rate is $20 \mathrm{mV} \mathrm{s}^{-1}$

shown in Eqs. 1-5. Equations 1, 3, and 4 correspond to the conversion of $\mathrm{Cu}$ and $\mathrm{Ni}$ to +2 valency, and Eqs. 2 and 5 correspond to the conversion of +2 to +3 valency $[48,53,54]$. As shown in Fig. 5a, the peak currents corresponding to Eqs. 1, 3, and 4 decrease with the cycle number and even finally disappear while the peak currents corresponding to Eqs. 2 and 5 increase with increases in the cycle number and reach constant values. Therefore, the activation results in the active sites on electrode surface follow the reversible processes in Eqs. 2 and 5 by 60 -cycle CVs. Additionally, $\mathrm{Cu}$ (III) and Ni (III) formed in the positive scan are used as catalysts to detect glucose as shown in Fig. 5b. The addition of glucose leads to an increase in the peak current due to the oxidation of glucose by $\mathrm{Cu}$ (III) and $\mathrm{Ni}$ (III) based on Eqs. 6 and 7 [48, 53]. For comparison purposes, the $\mathrm{CV}$ curves of $\mathrm{Ni} / \mathrm{C}$ on $\mathrm{Ni}$ foam and raw $\mathrm{Cu}$ foam are shown in Fig. S6. When compared with those on the $\mathrm{Ni} / \mathrm{C}$, we concluded that the redox peaks on $\mathrm{CuNi} / \mathrm{C}$ are hybrids of those on $\mathrm{Ni}$ and $\mathrm{Cu}$ that convert to high valence and turn back in the positive scan and subsequent negative scan.

The SEM images of activated $\mathrm{CuNi} / \mathrm{C}$ electrodes (shown in Fig. S7) verify the formation of hydroxides that resemble pine needles (Fig. S7b) and evidently differs from the raw morphology (Fig. S7a). However, the needlelike hydroxides do not exhibit any interference with the array structure of raw CuNi/C electrode as shown in Fig. 3c, d. The Raman spectra of the activated electrodes (shown in Fig. S8) indicate the existence of $\mathrm{NiOOH}$ and $\mathrm{CuOOH}$, and this is consistent with the $\mathrm{CV}$ results. The higher $\mathrm{D}$ peak when compared with $\mathrm{G}$ peak demonstrates that the carbon in the nanosheets is amorphous.

Activation of $\mathrm{CuNi} / \mathrm{C}$ is as follows:

$\mathrm{Ni}+2 \mathrm{OH}^{-} \rightarrow \mathrm{Ni}(\mathrm{OH})_{2}+2 \mathrm{e}^{-}$
$\mathrm{Ni}(\mathrm{OH})_{2}+\mathrm{OH}^{-} \leftrightarrow \mathrm{NiOOH}+\mathrm{H}_{2} \mathrm{O}+\mathrm{e}^{-}$

$\mathrm{Cu}+2 \mathrm{OH}^{-} \rightarrow \mathrm{CuO}+\mathrm{H}_{2} \mathrm{O}+2 \mathrm{e}^{-}$

$\mathrm{CuO}+\mathrm{H}_{2} \mathrm{O} \rightarrow \mathrm{Cu}(\mathrm{OH})_{2}$

$\mathrm{Cu}(\mathrm{OH})_{2}+\mathrm{OH}^{-} \leftrightarrow \mathrm{CuOOH}+\mathrm{H}_{2} \mathrm{O}+\mathrm{e}^{-}$

Glucose detection is as follows:

$\mathrm{NiOOH}+$ glucose $\rightarrow \mathrm{Ni}(\mathrm{OH})_{2}+$ gluconolactone

$\mathrm{CuOOH}+$ glucose $\rightarrow \mathrm{Cu}(\mathrm{OH})_{2}+$ gluconolactone

The electrochemical characteristics of activated $\mathrm{CuNi} / \mathrm{C}$ electrodes for detecting glucose were investigated. The $\mathrm{CV}$ curves of the electrodes in $0.1 \mathrm{M} \mathrm{NaOH}$ without and with $0.4 \mathrm{mM}$ glucose are shown in Fig. S9a, b, respectively. The peak currents increase with increases in the scan rates in both the electrolytes, and the values in the glucose-containing electrolyte exceed those without glucose at the same scan rates. The additional currents are attributed to the oxidation of glucose $[48,53,54]$, and this is verified by the $\mathrm{CV}$ curves of the electrode in $0.1 \mathrm{M} \mathrm{NaOH}$ with various concentrations of glucose at a constant scan rate as shown in Fig. S9c. The oxidizing current peak increases with increases in the glucose concentration, while the reduction current is steady due to the irreversible processes of glucose oxidation in Eqs. 6 and 7. Furthermore, the relationship between the peak current with the scan rates was examined and is shown in Fig. S9d. Both the anodic and cathodic peak currents are directly proportional to the square root of scan rates, and this implies a typical diffusion-controlled process.

In order to select a reasonable potential for glucose detection, the amperometric responses of consecutively adding $8 \mu \mathrm{M}$ glucose into $0.1 \mathrm{M} \mathrm{NaOH}$ at different potentials are investigated, and the results are shown in Fig. 6a. The detection potential should cater to the 

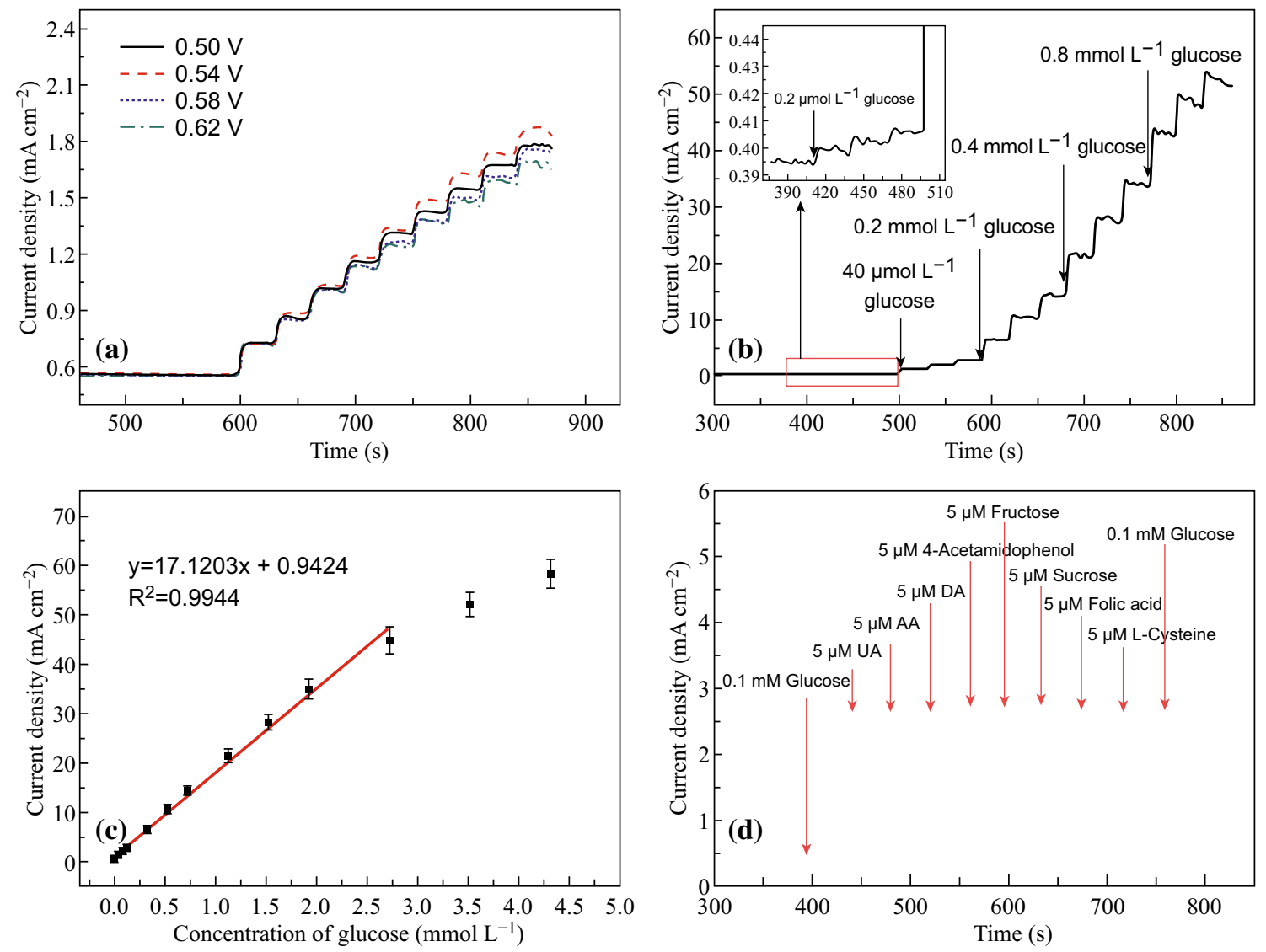

Fig. 6 a Effects of various potentials on the amperometric response of $\mathrm{CuNi} / \mathrm{C}$ electrodes given the successive addition of $8 \mu \mathrm{M}$ glucose. b Amperometric responses of $\mathrm{CuNi} / \mathrm{C}$ electrodes given the successive addition of glucose at $0.54 \mathrm{~V}$. The left inset shows partial amplification of the amperometric response to low glucose concentration. $\mathbf{c}$ The corresponding calibration curve of the response current density relative to glucose concentration. $\mathbf{d}$ Interference test performed on CuNi/C electrodes by adding $0.1 \mathrm{mM}$ glucose, $5 \mu \mathrm{M}$ DA, $5 \mu \mathrm{M} \mathrm{AA} 52 \mu \mathrm{M}$ UA, $5 \mu \mathrm{M}$ acetaminophen, $5 \mu \mathrm{M}$ fructose, $5 \mu \mathrm{M}$ sucrose, $5 \mu \mathrm{M}$ folic acid, and $5 \mu \mathrm{M}$ L-cysteine into $0.1 \mathrm{M} \mathrm{NaOH}$ at $0.54 \mathrm{~V}$

formation of high-valent $\mathrm{Cu}$ and $\mathrm{Ni}$ species as well as avoid oxygen evolution. Based on this, the potentials of 0.50 , $0.54,0.58$, and $0.62 \mathrm{~V}$ are selected for comparison purposes in the present study. Evidently, the glucose oxidation at $0.54 \mathrm{~V}$ results in the maximum current response, and thus $0.54 \mathrm{~V}$ is set as the working potential in the subsequent investigation. The influence of $\mathrm{pH}$ value on the glucose determination was examined by the amperometric responses of $\mathrm{CuNi} / \mathrm{C}$ electrodes given the successive addition of $20 \mu \mathrm{M}$ glucose into $\mathrm{NaOH}$ solution with different concentrations at $0.54 \mathrm{~V}$ as shown in Fig. S10. It is observed that the response current is the highest and most stable in the solution of $0.1 \mathrm{M} \mathrm{NaOH}$. In contrast, the response currents are negligible at lower $\mathrm{pH}$ values (e.g., $\mathrm{pH}=7,9$, 11 ), and the response current fluctuates sharply at higher $\mathrm{pH}$ value (e.g., $\mathrm{pH}=14$ ). Therefore, $0.1 \mathrm{NaOH}$ is used as the matrix solution of glucose detection.

The amperometric response to successive additions of glucose with specific concentrations into $0.1 \mathrm{M} \mathrm{NaOH}$ at $0.54 \mathrm{~V}$ was measured to study the detection limit, linear range, and sensitivity of $\mathrm{CuNi} / \mathrm{C}$ electrode. The $i-t$ curves are shown in Fig. 6b, and the inset shows the enlarged view of the responses for trace addition $(0.2 \mu \mathrm{M})$. The detection limit is calculated based on the lowest added concentration that presents a clear response. In the present study, the detection limit is $0.067 \mu \mathrm{M}$ with a signal to noise ratio of 3 $(\mathrm{S} / \mathrm{N}=3)$. The relationship that steady currents based on specific glucose concentrations (as shown in Fig. 6c) indicates a linear range from $0.2 \mu \mathrm{M}$ to $2.72 \mathrm{mM}\left(R^{2}=0.9953\right)$ and presents a sensitivity of $17.12 \mathrm{~mA} \mathrm{mM} \mathrm{mm}^{-1}$. A comprehensive comparison between our $\mathrm{CuNi} / \mathrm{C}$ electrodes and reported CuNi-based glucose sensors is shown in Table 1 . The linear range of our electrode is slightly inferior. However, the reasonable detection limit and ultra-high sensitivity are its advantages when compared with previous electrodes. The $\mathrm{CuNi} / \mathrm{C}$ electrodes possess the highest sensitivity $\left(17.12 \mathrm{mM}^{-1} \mathrm{~cm}^{-2}\right)$, and this is at least an order higher than the other results. The linear range of $\mathrm{CuNi} / \mathrm{C}$ $(0.2-2720.6 \mu \mathrm{M})$ is slightly inferior when compared with those in extant studies. Nevertheless, it considerably 
Table 1 Comparison of $\mathrm{CuNi} / \mathrm{C}$ glucose sensor with previously reported Ni-based non-enzymatic glucose sensors

\begin{tabular}{lllclc}
\hline Electrode composition & $\begin{array}{l}\text { Working potential } \\
(\mathrm{V} \text { vs. Ag/AgCl) }\end{array}$ & $\begin{array}{l}\text { Sensitivity mA } \\
\left(\mathrm{mM}^{-1} \mathrm{~cm}^{-2}\right)\end{array}$ & $\begin{array}{l}\text { Linear range } \\
(\mu \mathrm{M})\end{array}$ & $\begin{array}{l}\text { Detection limit } \\
(\mu \mathrm{M})\end{array}$ & $\begin{array}{l}\text { Self-supported } \\
\text { or not }\end{array}$ \\
\hline CuNi/MWCNTs [38] & 0.450 & 1.4702 & $0.962-5000$ & 0.0025 & No \\
CuNi/MWCNTs [37] & 0.575 & 2.4370 & $2000-8000$ & 0.0250 & Yes \\
CuNi [35] & 0.550 & 0.01916 & $7-23670$ & 2.3000 & Yes \\
CuNi [36] & 0.600 & 1.5909 & $10-3200$ & 5.0 & Yes \\
This work & 0.540 & 17.1203 & $0.2-2720.6$ & 0.06667 & Yes \\
\hline
\end{tabular}

Table 2 Adding standard recovery results to determine glucose in blood serum samples

\begin{tabular}{llllllll}
\hline Sample & $\begin{array}{l}\text { Hospital results } \\
(\mathrm{mM})\end{array}$ & $\begin{array}{l}\text { Our results (uncertainty) } \\
(\mathrm{mM})\end{array}$ & $\begin{array}{l}\text { RSD } \\
(\%)\end{array}$ & $\begin{array}{l}\text { Added amount } \\
(\mathrm{mM})\end{array}$ & $\begin{array}{l}\text { Our results (uncertainty) } \\
(\mathrm{mM})\end{array}$ & $\begin{array}{l}\text { Recovery } \\
(\%)\end{array}$ & $\begin{array}{l}\text { RSD } \\
(\%)\end{array}$ \\
\hline 1 & 6.050 & $6.160(0.12)$ & 1.16 & 4.0 & $10.32(0.15)$ & 106.7 \\
2 & 8.190 & $7.970(0.18)$ & 2.35 & 6.0 & $14.40(0.14)$ & 103.5 \\
3 & 15.77 & $15.61(0.17)$ & 2.61 & 8.0 & $23.69(0.16)$ & 98.96 \\
\hline
\end{tabular}

${ }^{a}$ The standard uncertainty of glucose-6-phosphate dehydrogenase method to detect glucose is $0.11-0.18$

exceeds those of the pristine $\mathrm{Ni} / \mathrm{C}$ electrodes (approximately $0.15-1480 \mu \mathrm{M}$ ) reported in a previous study [43].

The selectivity of $\mathrm{CuNi} / \mathrm{C}$ electrode in glucose detection was investigated by introducing AA, DA, UA, acetaminophen, fructose, sucrose, folic acid, and L-cysteine into electrolytes to inspect its ability to discriminate between interference species. Figure $6 \mathrm{~d}$ shows the amperometric responses of $\mathrm{CuNi} / \mathrm{C}$ electrode toward the electrolyte while adding $5 \mu \mathrm{M}$ AA, $5 \mu \mathrm{M}$ DA, $5 \mu \mathrm{M} \mathrm{UA}, 5 \mu \mathrm{M}$ acetaminophen, $5 \mu \mathrm{M}$ fructose, $5 \mu \mathrm{M}$ sucrose, $5 \mu \mathrm{M}$ folic acid, $5 \mu \mathrm{M}$ L-cysteine, and $0.1 \mathrm{mM}$ glucose into $0.1 \mathrm{M}$ $\mathrm{NaOH}$ solution at $0.54 \mathrm{~V}$. Evidently, the jamming signals from the interferents are almost negligible when compared with the response to glucose. The same response currents of $\mathrm{CuNi} / \mathrm{C}$ to glucose between the initial $0.1 \mathrm{mM}$ addition and the final addition after the interfering species suggest good reliability. Furthermore, the feasibility of $\mathrm{CuNi} / \mathrm{C}$ in physiological environments was evaluated by the tolerance of chloride poisoning. The almost coincident curve patterns of CVs (Fig. S11) and amperometric responses (inset of Fig. S11) demonstrate the high tolerance of $\mathrm{CuNi} / \mathrm{C}$ toward chloride ions.

Three significant properties, namely, reusability, reproducibility, and stability of $\mathrm{CuNi} / \mathrm{C}$ were investigated by inspecting amperometric responses in various situations as shown in Fig. S12. A $\mathrm{CuNi} / \mathrm{C}$ was used to detect the reusability of the addition of $0.2 \mathrm{mM}$ glucose five times as shown in Fig. S12a. The low relative standard deviation (RSD) approximately $2.07 \%$ of the five response currents reveals the good reusability of $\mathrm{CuNi} / \mathrm{C}$ for glucose sensing. Similarly, the same analysis was performed on five electrodes to inspect the reproducibility of $\mathrm{CuNi} / \mathrm{C}$ as shown in
Fig. S12b. The fair RSD approximately $3.01 \%$ of the five response currents suggests good consistency of the electrodes. The stability of $\mathrm{CuNi} / \mathrm{C}$ electrodes was inspected by testing the current response to $8 \mu \mathrm{M}$ glucose every 5 days in the 60-day period as shown in Fig. S12c. The response currents of the electrode retain $90 \%$ of the initial value through 60 days, and this reveals its excellent long-term stability. The irregular degradation of response current is ascribed to the room temperature variation. Although the electrode process is sensitive to temperature, we continue to conduct measurements without a thermostat, to imitate real operating conditions. However, the current density decay does not exceed $8 \%$ in the long stability test. The attractive merits of reusability, reproducibility, and stability suggest that $\mathrm{CuNi} / \mathrm{C}$ electrodes are a good alternative for practical glucose detection.

In order to further verify its practicality, human blood serum was tested by a $\mathrm{CuNi} / \mathrm{C}$ electrode by using amperometric response. The serum $(30 \mu \mathrm{L})$ obtained from a hospital without any further treatment was added into $0.1 \mathrm{M} \mathrm{NaOH}$ solution $(10 \mathrm{~mL})$, and the sample was measured using a potentiostatic method at $0.54 \mathrm{~V}$ (vs. Ag/ $\mathrm{AgCl}$ ) in a three-electrode cell (a Pt foil as counter electrode). The glucose concentrations of serum are obtained by measuring their response currents in $\mathrm{NaOH}$ matrix solution, and thus it is unnecessary to test their CVs although amperometric responses are recorded. Conversely, the $\mathrm{CV}$ measurement is not conducted on the asprepared serum samples, and amperometric responses are tested for sustaining less than 30 s. Figure S13 shows the amperometric response (at $0.54 \mathrm{~V}$ ) of serum sample 1 for a test. As shown in Table 2, our results are in agreement with 
the results obtained by clinical reports (with respect to the method of glucose-6-phosphate dehydrogenase) in hospitals. The recovery assessed by standard additions of glucose to the serum samples was close to $100 \%$, and this implies that the $\mathrm{CuNi} / \mathrm{C}$ sensors are promising in terms of glucose detection with appealing accuracy.

\section{Conclusion}

In this study, $\mathrm{CuNi} / \mathrm{C}$ nanosheet arrays on $\mathrm{Ni}$ foam are prepared by electrodepositing $\mathrm{Cu}$ on a Ni-MOF derivate. Physical measurements results indicate that $\mathrm{Cu}$ nanoparticles are homogeneously distributed on the $\mathrm{Ni} / \mathrm{C}$ nanosheets without interference to the array structure. The $\mathrm{CuNi} / \mathrm{C}$ self-supported electrodes are applied as electrochemical sensors to detect glucose. The electrochemical results demonstrate that the electrodes possess a detection limit of $0.067 \mu \mathrm{M}$, a linear range from $0.2 \mu \mathrm{M}$ to $2.72 \mathrm{mM}$, and a sensitivity of $17.12 \mathrm{~mA} \mathrm{mM} \mathrm{cm}^{-2}$, and that their behavior is better than that of previous $\mathrm{Ni} / \mathrm{C}$ electrodes [43]. The tolerance of $\mathrm{CuNi} / \mathrm{C}$ toward AA, DA, UA, and chloride ions reveals its good selectivity and resistance to poison. The most important advantages of this sensor include its good reusability, reproducibility, and stability given the controllable preparation of electrodes and the stable chemical state on their surface. The detection of glucose in human blood serum presents results similar to those obtained from the method of glucose-6-phosphate dehydrogenase. All the results indicate that the prepared $\mathrm{CuNi} / \mathrm{C}$ electrodes are good alternatives for non-enzymatic sensors of glucose detection.

Acknowledgements This work was supported by the National Natural Science Foundation of China (No. 21776052), the Natural Science Foundation of Heilongjiang Province (No. QC2016010) and the Fundamental Research Funds for the Central Universities (No. HIT. IBRSEM. A. 201407).

Open Access This article is distributed under the terms of the Creative Commons Attribution 4.0 International License (http://crea tivecommons.org/licenses/by/4.0/), which permits unrestricted use, distribution, and reproduction in any medium, provided you give appropriate credit to the original author(s) and the source, provide a link to the Creative Commons license, and indicate if changes were made.

\section{References}

1. X.M. Gao, X. Zhang, H. Peng, L. Wu, W.H. Bai, G.S. Jin, R.Q. Wu, P.K. Hang, Chu, In situ synthesis of $\mathrm{Ni}(\mathrm{OH})_{2} / \mathrm{TiO}_{2}$ composite film on NiTi alloy for non-enzymatic glucose sensing. Sens. Actuators B 232, 150-157 (2016). https://doi.org/10.1016/j. snb.2016.03.122
2. F.J. Garcia-Garcia, P. Salazar, F. Yubero, A.R. González-Elipe, Non-enzymatic glucose electrochemical sensor made of porous $\mathrm{NiO}$ thin films prepared by reactive magnetron sputtering at oblique angles. Electrochim. Acta 201, 38-44 (2016). https://doi. org/10.1016/j.electacta.2016.03.193

3. Y. Zhao, L.Z. Fan, B. Hong, J.L. Ren, M.S. Zhang, Q.M. Que, J. Y. Ji, Nonenzymatic detection of glucose using three-dimensional $\mathrm{PtNi}$ nanoclusters electrodeposited on the multiwalled carbon nanotubes. Sens. Actuators B 231, 800-810 (2016). https://doi. org/10.1016/j.snb.2016.03.115

4. S.Q. Ci, T.Z. Huang, Z.H. Wen, S.M. Cui, S. Mao, D.A. Steeber, J.H. Chen, Nickel oxide hollow microsphere for non-enzyme glucose detection. Biosens. Bioelectron. 54, 251-257 (2014). https://doi.org/10.1016/j.bios.2013.11.006

5. J. Zhao, L. Wei, C. Peng, Y. Su, Z. Yang, L. Zhang, H. Wei, Y. Zhang, A non-enzymatic glucose sensor based on the composite of cubic $\mathrm{Cu}$ nanoparticles and arc-synthesized multi-walled carbon nanotubes. Biosens. Bioelectron. 47(17), 86-91 (2013). https://doi.org/10.1016/j.bios.2013.02.032

6. G.F. Wang, X.P. He, L.L. Wang, A.X. Gu, Y. Huang, B. Fang, B. Y. Geng, X.J. Zhang, Non-enzymatic electrochemical sensing of glucose. Microchim. Acta 180(3), 161-186 (2013). https://doi. org/10.1007/s00604-012-0923-1

7. K. Tian, M. Prestgard, A. Tiwari, A review of recent advances in nonenzymatic glucose sensors. Mater. Sci. Eng. C 41, 100-118 (2014). https://doi.org/10.1016/j.msec.2014.04.013

8. S.A. Zaidi, J.H. Shin, Recent developments in nanostructure based electrochemical glucose sensors. Talanta 149, 30-42 (2016). https://doi.org/10.1016/j.talanta.2015.11.033

9. S.P. Singh, S.K. Pandey, J. Singh, S. Srivastava, S. Sachan, S.K. Singh, Biomedical perspective of electrochemical nanobiosensor. Nano-Micro Lett. 8(3), 193-203 (2016). https://doi.org/10.1007/ s40820-015-0077-x

10. R.A. Soomro, A. Nafady, Z.H. Ibupoto, S.T.H. Sirajuddin, M. Sherazi, M.I.Abro Willander, Development of sensitive non-enzymatic glucose sensor using complex nanostructures of cobalt oxide. Mater. Sci. Semicond. Process. 34, 373-381 (2015). https://doi.org/10.1016/j.mssp.2015.02.055

11. R.A. Soomro, Z.H. Ibupoto, M.I. Sirajuddin, M.Willander Abro, Electrochemical sensing of glucose based on novel hedgehog-like $\mathrm{NiO}$ nanostructures. Sens. Actuators B 209, 966-974 (2015). https://doi.org/10.1016/j.snb.2014.12.050

12. H. Shekarchizadeh, M. Kadivar, A.A. Ensafi, Rapid nonenzymatic monitoring of glucose and fructose using a $\mathrm{CuO} / \mathrm{multi}-$ walled carbon nanotube nanocomposite-modified glassy carbon electrode. Chin. J. Catal. 34(6), 1208-1215 (2013). https://doi. org/10.1016/S1872-2067(12)60586-5

13. A.A. Ensafi, M.M. Abarghoui, B. Rezaei, A new non-enzymatic glucose sensor based on copper/porous silicon nanocomposite. Electrochim. Acta 123, 219-226 (2014). https://doi.org/10.1016/ j.electacta.2014.01.031

14. K.E. Toghill, L. Xiao, M.A. Phillips, R.G. Compton, The nonenzymatic determination of glucose using an electrolytically fabricated nickel microparticle modified boron-doped diamond electrode or nickel foil electrode. Sens. Actuators B 147, 642-652 (2010). https://doi.org/10.1016/j.snb.2010.03.091

15. A.A. Ensafi, M. Jafari-Asl, N. Dorostkar, M. Ghiaci, M.V. Martínez-Huerta, J.L.G. Fierro, The fabrication and characterization of $\mathrm{Cu}$-nanoparticle immobilization on a hybrid Chitosan derivative-carbon support as a novel electrochemical sensor: application for the sensitive enzymeless oxidation of glucose and reduction of hydrogen peroxide. J. Mater. Chem. B 2(6), 706-717 (2014). https://doi.org/10.1039/C3TB21434F

16. S.K. Annamalai, B. Palani, K.C. Pillai, Highly stable and redox active nano copper species stabilized functionalized-multiwalled carbon nanotube/chitosan modified electrode for efficient 
hydrogen peroxide detection. Colloids Surf. A 395, 207-216 (2012). https://doi.org/10.1016/j.colsurfa.2011.12.032

17. A.A. Ensafi, Z. Ahmadi, M. Jafari-Asl, B. Rezaei, Graphene nanosheets functionalized with Nile blue as a stable support for the oxidation of glucose and reduction of oxygen based on redox replacement of Pd-nanoparticles via nickel oxide. Electrochim. Acta 173, 619-629 (2015). https://doi.org/10.1016/j.electacta. 2015.05.109

18. Q. Yu, Z. Shi, X.Y. Liu, S.L. Luo, W.Z. Wei, A nonenzymatic hydrogen peroxide sensor based on chitosan-copper complexes modified multi-wall carbon nanotubes ionic liquid electrode. J. Electroanal. Chem. 655(1), 92-95 (2011). https://doi.org/10. 1016/j.jelechem.2010.12.030

19. A.A. Ensafi, N. Zandi-Atashbar, B. Rezaei, M. Ghiaci, M. Taghizadeh, Silver nanoparticles decorated carboxylate functionalized $\mathrm{SiO}_{2}$, new nanocomposites for non-enzymatic detection of glucose and hydrogen peroxide. Electrochim. Acta 214, 208-216 (2016). https://doi.org/10.1016/j.electacta.2016.08.047

20. H. Mei, W.Q. Wu, B.B. Yu, H.M. Wu, S.F. Wang, Q.H. Xia, Nonenzymatic electrochemical sensor based on Fe@Pt core-shell nanoparticles for hydrogen peroxide, glucose and formaldehyde. Sens. Actuators B 223, 68-75 (2016). https://doi.org/10.1016/j. snb.2015.09.044

21. M. Ghiaci, M. Tghizadeh, A.A. Ensafi, N. Zandi-Atashbar, B. Rezaei, Silver nanoparticles decorated anchored type ligands as new electrochemical sensors for glucose detection. J. Taiwan Inst. Chem. Eng. 63, 39-45 (2016). https://doi.org/10.1016/j.jtice. 2016.03.013

22. V. Mania, R. Devasenathipathy, S.-M. Chen, S.-F. Wang, P. Devic, Y. Tai, Electrodeposition of copper nanoparticles using pectin scaffold at graphene nanosheets for electrochemical sensing of glucose and hydrogen peroxide. Electrochim. Acta 176, 804-810 (2015). https://doi.org/10.1016/j.electacta.2015.07. 098

23. A.A. Ensafi, N. Zandi-Atashbar, B. Rezaei, M. Ghiaci, M.E. Chermahini, P. Moshiri, Non-enzymatic glucose electrochemical sensor based on silver nanoparticle decorated organic functionalized multiwall carbon nanotubes. RSC Adv. 6(65), 6092660932 (2016). https://doi.org/10.1039/C6RA10698F

24. Y. Zhang, L. Su, D. Manuzzi, H.V.E. Monteros, W. Jia, D. Huo, C. Hou, Y. Lei, Ultrasensitive and selective non-enzymatic glucose detection using copper nanowires. Biosens. Bioelectron. 31 (1), 426-432 (2012). https://doi.org/10.1016/j.bios.2011.11.006

25. J. Zhao, L. Wei, C. Peng, Y. Su, Z. Yang, L. Zhang, H. Wei, Y. Zhang, A non-enzymatic glucose sensor based on the composite of cubic $\mathrm{Cu}$ nanoparticles and arc-synthesized multi-walled carbon nanotubes. Biosens. Bioelectron. 47(17), 86-91 (2013). https://doi.org/10.1016/j.bios.2013.02.032

26. S.S. Mahshid, S. Mahshid, D. Abolghasem, M. Ghorbanib, L. Yang, S. Luo, Q. Cai, Template-based electrodeposition of Pt/Ni nanowires and its catalytic activity towards glucose oxidation. Electrochim. Acta 58, 551-555 (2011). https://doi.org/10.1016/j. electacta.2011.09.083

27. S.S. Mahshid, S. Mahshid, D. Abolghasem, M. Ghorbanib, L. Yang, S. Luo, Q. Cai, Electrodeposition and electrocatalytic properties of $\mathrm{Pt} / \mathrm{Ni}-\mathrm{Co}$ nanowires for non-enzymatic glucose detection. J. Alloys Compd. 554, 169-176 (2013). https://doi.org/ 10.1016/j.jallcom.2012.10.186

28. Y. Zhang, Y. Liu, L. Su, Z. Zhang, D. Huo, C. Hou, Y. Lei, CuO nanowires based sensitive and selective non-enzymatic glucose detection. Sens. Actuators B 191, 86-93 (2014). https://doi.org/ 10.1016/j.snb.2013.08.096

29. G. Wang, X. Lu, T. Zhai, Y. Ling, H. Wang, Y. Tong, Y. Li, Free-standing nickel oxide nanoflake arrays: synthesis and application for highly sensitive non-enzymatic glucose sensors.
Nanoscale 4(10), 3123-3127 (2012). https://doi.org/10.1039/ c2 $\mathrm{nr} 30302 \mathrm{~g}$

30. X. Guo, H. Zhang, C. Huo, X. Xu, Han, $\mathrm{Co}_{3} \mathrm{O}_{4}$ microspheres with free-standing nanofibers for high performance non-enzymatic glucose sensor. Analyst 138(22), 6727-6731 (2013). https://doi. org/10.1039/c3an01403g

31. K.K. Lee, P.Y. Loh, C.H. Sow, W.S. Chin, $\mathrm{CoOOH}$ nanosheets on cobalt substrate as a non-enzymatic glucose sensor. Electrochem. Commun. 20(1), 128-132 (2012). https://doi.org/10. 1016/j.elecom.2012.04.012

32. Q. Hou, L. Xu, X. Yin, Hu, Metal-organic framework templated synthesis of $\mathrm{Co}_{3} \mathrm{O}_{4}$ nanoparticles for direct glucose and $\mathrm{H}_{2} \mathrm{O}_{2}$ detection. Analyst 137(24), 2803-5808 (2012). https://doi.org/10. 1039/c2an35954e

33. C.W. Kung, C.Y. Lin, Y.H. Lai, R. Vittal, K.C. Ho, Cobalt oxide acicular nanorods with high sensitivity for the non-enzymatic detection of glucose. Biosens. Bioelectron. 27(1), 125-131 (2011). https://doi.org/10.1016/j.bios.2011.06.033

34. Y. Ding, Y. Wang, L. Su, M. Bellagamba, H. Zhang, Y. Lei, Electrospun $\mathrm{Co}_{3} \mathrm{O}_{4}$ nanofibers for sensitive and selective glucose detection. Biosens. Bioelectron. 26(2), 542-548 (2010). https:// doi.org/10.1016/j.bios.2010.07.050

35. B. Wang, S. Li, J. Liu, M. Yu, Preparation of nickel nanoparticle/graphene composites for non-enzymatic electrochemical glucose biosensor applications. Mater. Res. Bull. 49(1), 521-524 (2014). https://doi.org/10.1016/j.materresbull.2013.08.066

36. M. Yuan, A. Liu, M. Zhao, W. Dong, T. Zhao, J. Wang, W. Tang, Bimetallic $\mathrm{PdCu}$ nanoparticle decorated three-dimensional graphene hydrogel for non-enzymatic amperometric glucose sensor. Sens. Actuators B 190, 707-714 (2014). https://doi.org/10.1016/j. snb.2013.09.054

37. Y. Guo, Y. Wang, C. Zhao, Xu, Non-enzymatic glucose sensor based on three dimensional nickel oxide for enhanced sensitivity. Anal. Methods 5(7), 1644-1647 (2013). https://doi.org/10.1039/ c3ay00067b

38. Z. Fan, B. Liu, X. Liu, Z. Li, H. Wang, S. Yang, J. Wang, A flexible and disposable hybrid electrode based on $\mathrm{Cu}$ nanowires modified graphene transparent electrode for non-enzymatic glucose sensor. Electrochim. Acta 109, 602-608 (2013). https://doi. org/10.1016/j.electacta.2013.07.153

39. G.H. Wu, X.H. Song, Y.F. Wu, X.M. Chen, F. Luo, X. Chen, Non-enzymatic electrochemical glucose sensor based on platinum nanoflowers supported on graphene oxide. Talanta 105(4), 379-385 (2013). https://doi.org/10.1016/j.talanta.2012.10.066

40. M. Liu, R. Liu, W. Chen, Graphene wrapped $\mathrm{Cu}_{2} \mathrm{O}$ nanocubes: non-enzymatic electrochemical sensors for the detection of glucose and hydrogen peroxide with enhanced stability. Biosens. Bioelectron. 45, 206-212 (2013). https://doi.org/10.1016/j.bios. 2013.02.010

41. C. Karuppiah, S. Palanisamy, S.M. Chen, V. Veeramani, P. Periakaruppan, A novel enzymatic glucose biosensor and sensitive non-enzymatic hydrogen peroxide sensor based on graphene and cobalt oxide nanoparticles composite modified glassy carbon electrode. Sens. Actuators B 196, 450-456 (2014). https://doi.org/ 10.1016/j.snb.2014.02.034

42. K.E. Toghill, R.G. Compton, Electrochemical non-enzymatic glucose sensors: a perspective and an evaluation. Int. J. Electrochem. Sci. 5(9), 1246-1301 (2010). http://www.electro chemsci.org/papers/vol5/5091246.pdf

43. L. Zhang, Y.R. Ding, R.R. Li, C. Ye, G.Y. Zhao, Y. Wang, NiBased metal-organic framework derived $\mathrm{Ni} @ \mathrm{C}$ nanosheets on a $\mathrm{Ni}$ foam substrate as a supersensitive non-enzymatic glucose sensor. J. Mater. Chem. B 5(28), 5549-5555 (2017). https://doi. org/10.1039/C7TB01363A 
44. S.Y. Tee, C.P. Teng, E. Ye, Metal nanostructures for non-enzymatic glucose sensing. Mater. Sci. Eng. C 70, 1018-1030 (2017). https://doi.org/10.1016/j.msec.2016.04.009

45. P. Si, Y.J. Huang, T.H. Wang, Nanomaterials for electrochemical non-enzymatic glucose biosensors. RSC Adv. 3(11), 3487-3502 (2013). https://doi.org/10.1039/c2ra22360k

46. Z.H. Ibupoto, A. Nafady, R.A. Soomro, Glycine-assisted synthesis of $\mathrm{NiO}$ hollow cage-like nanostructures for sensitive nonenzymatic glucose sensing. RSC Adv. 5(24), 18773-18781 (2015). https://doi.org/10.1039/C4RA15858J

47. S.F. Tong, Y.H. Xu, Z.X. Zhang, Dendritic bimetallic nanostructures supported on self-assembled titanate films for sensor application. J. Phys. Chem. 114(49), 20925-20931 (2010). https://doi.org/10.1021/jp1035772

48. R.M. Ding, J.P. Liu, J. Jiang, Tailored Ni-Cu alloy hierarchical porous nanowire as a potential efficient catalyst for DMFCs. Catal. Sci. Technol. 1(8), 1406-1411 (2011). https://doi.org/10. 1039/c1cy00164g

49. L. Wang, Q.Y. Zhang, S.L. Chen, Electrochemical sensing and biosensing platform based on biomass-derived macroporous carbon materials. Anal. Chem. 86(3), 1414-1421 (2014). https:// doi.org/10.1021/ac401563m
50. X.L. Li, J.Y. Yao, F.L. Liu, Nickel/Copper nanoparticles modified $\mathrm{TiO}_{2}$ nanotubes for non-enzymatic glucose biosensors. Sens. Actuators B 181, 501-508 (2013). https://doi.org/10.1016/j.snb. 2013.02.035

51. K.C. Lin, Y.C. Lin, S.M. Chen, A highly sensitive nonenzymatic glucose sensor based on multi-walled carbon nanotubes decorated with nickel and copper nanoparticles. Electrochim. Acta 96, 164172 (2013). https://doi.org/10.1016/j.electacta.2013.02.098

52. W. Yi, J. Liu, H.B. Chen, Copper/nickel nanoparticle decorated carbon nanotubes for nonenzymatic glucose biosensor. J. Solid State Electrochem. 19(5), 1511-1521 (2015). https://doi.org/10. 1007/s10008-015-2766-2

53. P. Druska, H.H. Strehblow, S. Golledge, A surface analytical examination of passive layers on $\mathrm{Cu} / \mathrm{Ni}$ alloys. Alkaline solution. Corros. Sci. 38(6), 835-851 (1996). https://doi.org/10.1016/0010938X(96)00170-9

54. M. Jafarian, F. Forouzandeh, I. Danaee, Electrocatalytic oxidation of glucose on $\mathrm{Ni}$ and $\mathrm{NiCu}$ alloy modified glassy carbon electrode. J. Solid State Electrochem. 13(8), 1171-1179 (2008). https://doi.org/10.1007/s10008-008-0632-1 